\title{
Multi-satellite aerosol observations in the vicinity of clouds
}

\author{
T. Várnai ${ }^{1,2}$, A. Marshak ${ }^{2}$, and W. Yang ${ }^{2,3}$ \\ ${ }^{1}$ University of Maryland Baltimore County, Joint Center for Earth System Technology, Baltimore, MD, USA \\ ${ }^{2}$ NASA Goddard Space Flight Center, Climate and Radiation Laboratory, Greenbelt, MD, USA \\ ${ }^{3}$ Universities Space Research Association, Columbia, MD, USA \\ Correspondence to: T. Várnai (tamas.varnai@nasa.gov)
}

Received: 8 November 2012 - Published in Atmos. Chem. Phys. Discuss.: 13 December 2012

Revised: 26 February 2013 - Accepted: 20 March 2013 - Published: 16 April 2013

\begin{abstract}
Improved characterization of aerosol properties in the vicinity of clouds is important for better understanding two critical aspects of climate: aerosol-cloud interactions and the direct radiative effect of aerosols. Satellite measurements have provided important insights into aerosol properties near clouds, but also suggested that the observations can be affected by 3-D radiative processes and instrument blurring not considered in current data interpretation methods. This study examines systematic cloud-related changes in particle properties and radiation fields that influence satellite measurements of aerosols in the vicinity of low-level maritime clouds. For this, the paper presents a statistical analysis of a yearlong global dataset of co-located MODIS and CALIOP observations and theoretical simulations. The results reveal that CALIOP-observed aerosol particle size and optical thickness, and MODIS-observed solar reflectance increase systematically in a wide transition zone around clouds. It is estimated that near-cloud changes in particle populations - including both aerosols and undetected cloud particles - are responsible for roughly two thirds of the observed increase in $0.55 \mu \mathrm{m}$ MODIS reflectance. The results also indicate that 3 -D radiative processes significantly contribute to near-cloud reflectance enhancements, while instrument blurring contributes significantly only within $1 \mathrm{~km}$ from clouds and then quickly diminishes with distance from clouds.
\end{abstract}

\section{Introduction}

This study examines satellite measurements of aerosols near low-level maritime clouds. The goal is to better understand cloud-related changes in aerosol properties, and to help re- duce the uncertainties that arise in aerosol measurements because current data interpretation methods do not consider 3-D radiative processes and instrument blurring near clouds. Improving the characterization of near-cloud aerosols is important for better understanding two critical aspects of climate: (i) aerosol-cloud interactions, which cause large uncertainties in assessing climate change and human impacts on climate (e.g., Charlson et al., 2007; Solomon et al., 2007); and (ii) direct radiative effect of aerosols, much of which occurs in the more than half of clear areas that lie within a few km from clouds (Twohy et al., 2009; Várnai and Marshak, 2009).

Accurate aerosol measurements near clouds are especially important because clouds are surrounded by a several $\mathrm{km}$ wide transition zone of systematically changing particle populations (including both aerosols and undetected cloud droplets) and radiation fields (Koren et al., 2007; Su et al., 2008; Redemann et al., 2009; Tackett and Di Girolamo, 2009; Várnai and Marshak, 2009, 2011). The observed particle changes come from a variety of sources ranging from aerosols swelling in humid air and the detrainment of cloudprocessed particles into the cloud-free environment to the presence of undetected cloud particles, for example in cloud fragments that have sheared off from adjacent clouds, in incipient or in decaying clouds, or in hesitant clouds that oscillate near saturation (Koren et al., 2009). The observed changes in radiation fields come partly from such particle changes, and partly from 3-D radiative processes (Wen et al., 2007, 2008) and instrument blurring caused by stray light contamination (Meister and McClain, 2010). To help better characterize the areas affected by clouds, Bar-Or et al. (2010, 2011) introduced a new metric "cloud field fraction", which is much larger than the corresponding cloud fraction. 
The present study examines these factors through a statistical analysis of data from two satellites and from two theoretical models. First, data from the Aqua satellite's MODIS (MODerate resolution Imaging Spectroradiometer) instrument provides cloud locations and solar reflectance fields near clouds. Second, data from the CALIPSO (CloudAerosol Lidar and Infrared Pathfinder Satellite Observations) satellite's CALIOP (Cloud-Aerosol Lidar with Orthogonal Polarization) lidar provides information on near-cloud particle changes without the complications of 3-D radiative processes and instrument blurring. Third, Monte Carlo radiative transfer simulations provide information on 3-D radiative processes near clouds. Fourth, simulations using known instrument characteristics provide estimates of blurring effects.

The outline of the paper is as follows. Section 2 looks at near-cloud changes in particle populations using CALIOP data, and Sect. 3 seeks signs of 3-D radiative effects in the spectral dependence of MODIS data. Next, the paper estimates the causes of near-cloud changes in MODIS reflectances by combining CALIOP and MODIS data in Sect. 4, and combining the observations with theoretical simulations in Sect. 5. Finally, Sect. 6 offers a brief summary.

\section{Particle changes near clouds}

As discussed in earlier studies, near-cloud changes in MODIS reflectances are intertwined with changes in particle populations (Koren et al., 2007; Redemann et al., 2009). The CALIOP lidar can help untangle these changes because it can characterize particle changes without the instrument blurring and 3-D radiative processes affecting MODIS data (Tackett and Di Girolamo, 2009; Várnai and Marshak, 2012; Yang et al., 2012). We note, however, that CALIOP data requires more averaging because of its much higher noise level.

Figure 1 illustrates near-cloud particle changes for a monthlong set of nighttime CALIOP data over all oceans between $60^{\circ} \mathrm{N}$ and $60^{\circ} \mathrm{S}$ latitudes. Panels a and b show 2-D CALIOP histograms for areas closer and farther than $5 \mathrm{~km}$ from the nearest cloud, respectively. The $5 \mathrm{~km}$ threshold was chosen because Várnai and Marshak $(2011,2012)$ found that roughly half of clear areas over oceans lie within $4-5 \mathrm{~km}$ from the nearest low cloud. The identical yellow arrows in panels a and $\mathrm{b}$ highlight that the 2-D CALIOP histogram shifts toward larger attenuated backscatter and color ratio values near clouds. Because backscatter is related to optical thickness and color ratio is related to particle size, the shift implies that particles become larger and have a greater optical thickness near clouds. These changes are consistent both with the presence of undetected cloud droplets and with aerosols swelling in the humid air near clouds.

We note, however, that while Twohy et al. (2009) found modest humidity increases to extend more than $4 \mathrm{~km}$ away from clouds, their study as well as Bar-Or et al. (2012) found

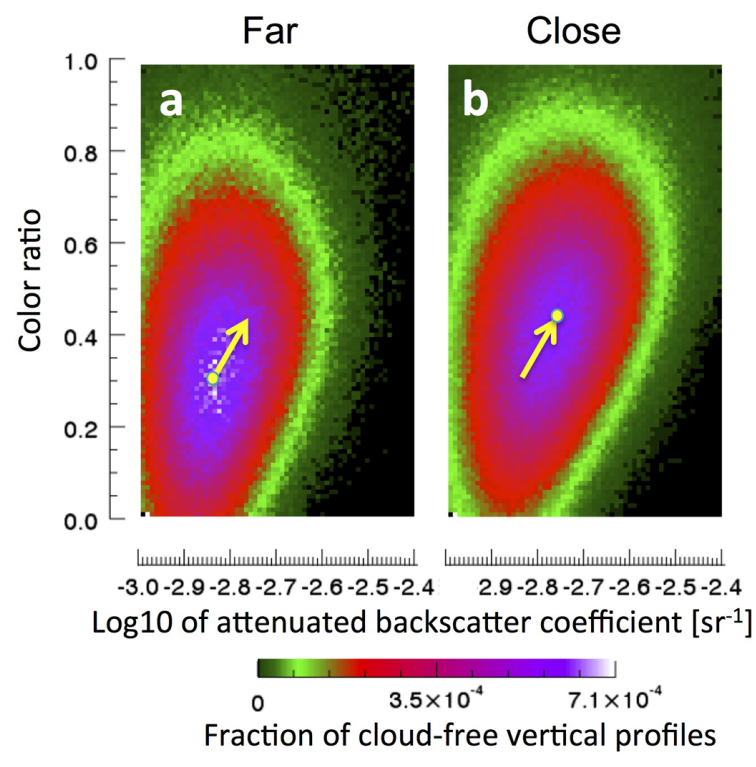

Fig. 1. Joint probability density functions (pdf) of color ratio (ratio of $1064 \mathrm{~nm}$ and $532 \mathrm{~nm}$ attenuated backscatters) and $532 \mathrm{~nm}$ attenuated backscatter coefficient vertically integrated below $3 \mathrm{~km}$ altitude. (a) cloud-free columns farther than $5 \mathrm{~km}$ from the nearest low cloud along the CALIOP track, (b) cloud-free columns closer than $5 \mathrm{~km}$ to the nearest low cloud. The origins of the identical yellow arrows indicate the mode of the left pdf, while the ends of the arrows indicate the mode of the right one. For the nighttime dataset analyzed in this figure, low clouds are detected using the Version 3 CALIOP vertical feature mask, and are defined as clouds for which CALIOP indicates a cloud top altitude of less than $3 \mathrm{~km}$.

the areas of highest relative humidity (>90\%) to be limited to less than a kilometer away from clouds, with the sharpest increases occurring within a few hundred meters from clouds. The large shifts between Fig. 1a and b reinforce the conclusion of earlier studies that the interpretation of near-cloud radiation fields must account for near-cloud changes in particle properties.

\section{Spectral dependence of solar reflectance}

We begin the analysis of MODIS solar reflectances by examining their spectral dependence. Near-cloud increases in particle size and 3-D radiative effects have opposite spectral influences on MODIS reflectances. Indeed, increases in particle size make the spectral dependence more flat - a tendency widely used for remote measurements of particle size distributions (e.g., Dubovik et al., 1995; Remer et al., 2005) - while the 3-D radiative process of bluing (Marshak et al., 2008) makes the spectral dependence steeper. The latter is due to radiation scattered by clouds and then scattered to the sensor by air molecules in nearby clear-sky columns, with molecular scattering being stronger at shorter wavelengths. 

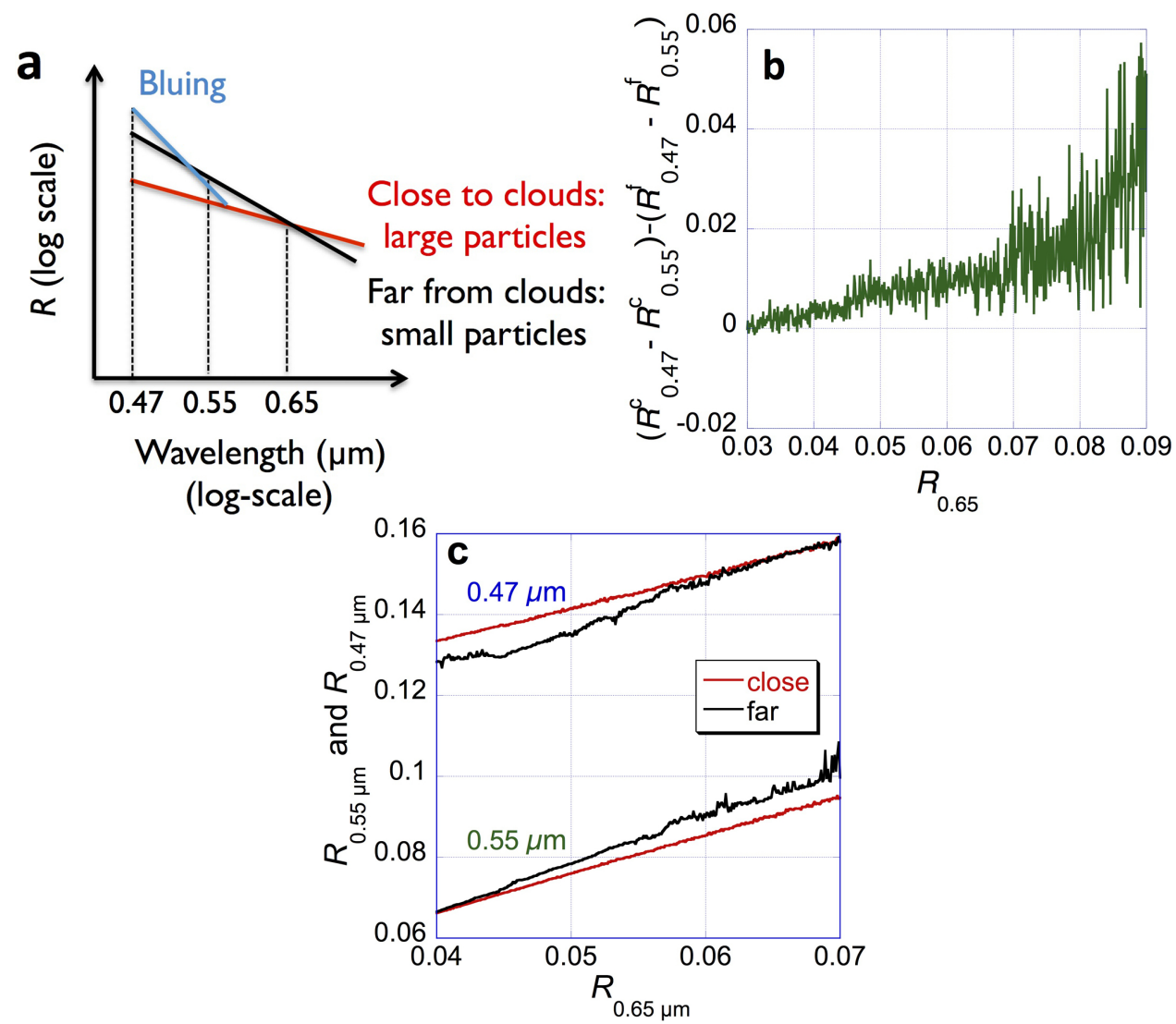

Fig. 2. (a) Schematic graph illustrating the average spectral dependence of clear sky solar reflectance close to clouds and far from clouds, given a reflectance at $0.65 \mu \mathrm{m}$. (b) Difference between the steepness of observed mean spectral dependence $\left(R_{0.47}-R_{0.55}\right)$ close to clouds (superscript "c") and far from clouds (superscript "f"), as a function of $R_{0.65}$. (c) Mean 0.47 and $0.55 \mu \mathrm{m}$ reflectances as a function of $0.65 \mu \mathrm{m}$ reflectance, close to clouds (red) and far from clouds (black). The close and far categories include areas that are less than or more than $5 \mathrm{~km}$ away from the nearest cloud, respectively. $R_{0.47}, R_{0.55}$, and $R_{0.65}$ are the mean reflectances observed by MODIS at $0.47,0.55$, and $0.65 \mu \mathrm{m}$ wavelengths.

Figure 2 examines the spectral dependence of MODIS nadir reflectances for a yearlong (November 2006-October 2007) dataset that covers all oceans using cloud-free pixels with a solar zenith angle near $30^{\circ}$. This figure and all subsequent figures use daytime data and the MODIS cloud mask that can detect clouds even outside the CALIOP track. Low clouds are defined as clouds with MODIS cloud top pressure greater than $700 \mathrm{hPa}$. While the altitude of the $700 \mathrm{hPa}$ pressure level may vary by hundreds of meters, it tends to be near $3 \mathrm{~km}$. (For single-layer clouds in our dataset, the mean CALIOP cloud top altitude at areas where MODIS indicates a cloud top pressure in the $690-710 \mathrm{hPa}$ range is $2.98 \mathrm{~km}$.) We note that throughout the study we use CALIOP Version 3 and MODIS Collection 5 products. The red and black lines in Fig. 2a schematically illustrate close to cloud and far from cloud spectral behaviors, respectively. They illustrate that given a certain reflectance at $0.65 \mu \mathrm{m}\left(R_{0.65}\right)$, we expect flatter spectral dependence and hence smaller difference $R_{0.47}-R_{0.55}$ close to clouds (red line) than far from clouds (black line), assuming that only the near-cloud particle size increases. As an opposite effect, the blue line illustrates the near-cloud bluing that should increase $R_{0.47}-R_{0.55}$ values near clouds. Panel b shows that for any typical clear-sky $R_{0.65}$ value, the observed mean difference $R_{0.47}-R_{0.55}$ is larger near clouds (upper index "c") than far from clouds (upper index "f") - that is, $\left(R_{0.47}^{\mathrm{c}}-R_{0.55}^{\mathrm{c}}\right)-\left(R_{0.47}^{\mathrm{f}}-R_{0.55}^{\mathrm{f}}\right)>0$. Panel c offers further insights by showing median 0.47 and $0.55 \mu \mathrm{m}$ reflectances close to and far from clouds $\left(R_{0.47}^{\mathrm{c}}, R_{0.47}^{\mathrm{f}}, R_{0.55}^{\mathrm{c}}\right.$, and $\left.R_{0.55}^{\mathrm{f}}\right)$ as a function of $R_{0.65}$. We assume that $R_{0.65}$ characterizes aerosol loading: low $R_{0.65}$ values correspond to clean areas with few atmospheric particles, while high $R_{0.65}$ values correspond to more aerosol laden areas. The lower two curves in panel c reveal that for low $R_{0.65}$, near-cloud processes (such as aerosol swelling) influence only a few particles and cannot make a large difference between $R_{0.55}^{\mathrm{f}}$ and $R_{0.55}^{\mathrm{c}}$. As particle concentration increases (larger $R_{0.65}$ ), $R_{0.55}^{\mathrm{f}}$ increasingly exceeds $R_{0.55}^{\mathrm{c}}$ due to the steeper spectral exponent associated with smaller particle size far from clouds. In principle, for low particle concentration (small $R_{0.65}$ ), near-cloud changes 

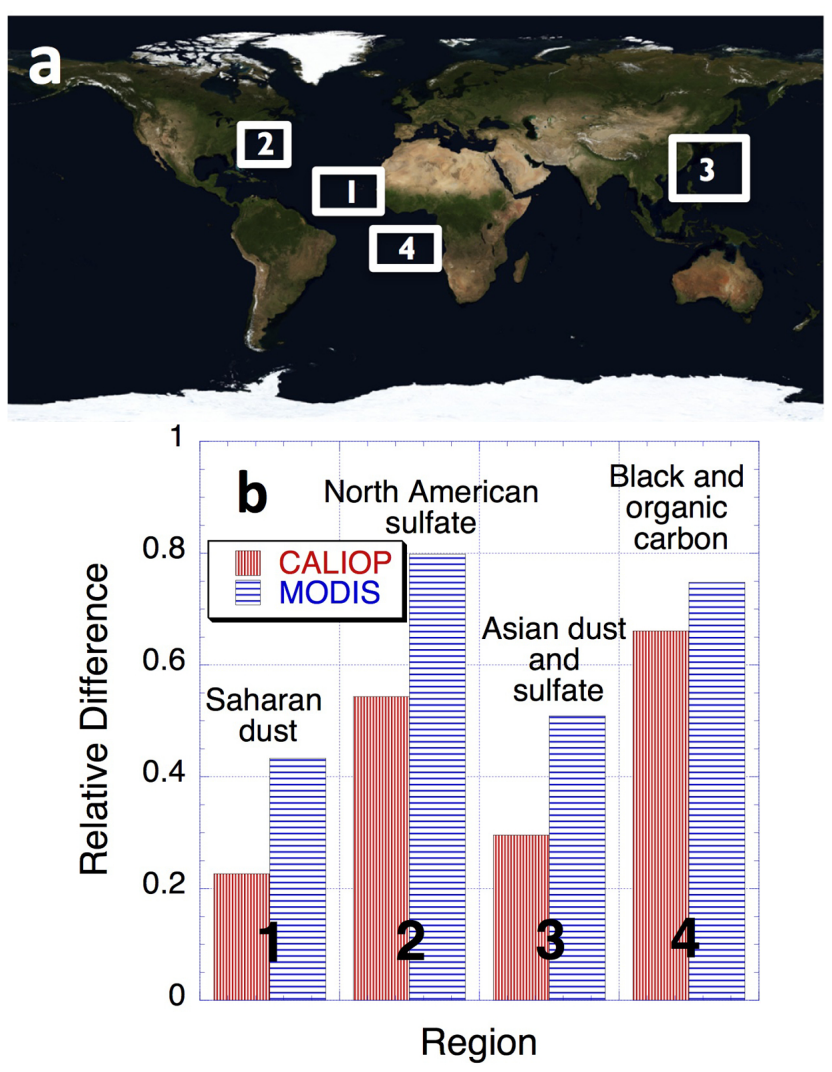

Fig. 3. Regional differences in near-cloud enhancements. (a) Geographical location of four regions dominated by different aerosol types. The coordinates of the four regions are as follows: 1: (5$\left.20^{\circ} \mathrm{N}, 15-45^{\circ} \mathrm{W}\right), 2:\left(25-45^{\circ} \mathrm{N}, 55-80^{\circ} \mathrm{W}\right), 3:\left(15-45^{\circ} \mathrm{N}, 110\right.$ $\left.140^{\circ} \mathrm{E}\right), 4:\left(0-20^{\circ} \mathrm{S}, 20^{\circ} \mathrm{W}-10^{\circ} \mathrm{E}\right)$. (b) Near-cloud relative enhancements of particle scattering in the four regions, as observed by CALIOP and MODIS. These relative enhancements (RE) are obtained using $\mathrm{RE}=\left(X_{\mathrm{d}<5 \mathrm{~km}}-X_{\mathrm{d}>5 \mathrm{~km}}\right) / X_{\mathrm{d}>5 \mathrm{~km}}$, where $X$ is the particle contribution to either $532 \mathrm{~nm}$ CALIOP backscatter $\left(\beta^{p}\right)$ or $0.55 \mu \mathrm{m}$ MODIS reflectance $\left(R^{p}\right)$, and $d$ is distance to the nearest cloud below the altitude of the $700 \mathrm{hPa}$ pressure level $(\sim 3 \mathrm{~km})$.

in particle size should not make much of a difference in $R_{0.47}$ either. Yet the two upper curves in panel c show that $R_{0.47}^{\mathrm{c}}$ even exceeds $R_{0.47}^{\mathrm{f}}$ for small $R_{0.65}$. This is consistent with a steep spectral dependence caused by a strong 3-D bluing enhancement near clouds at $0.47 \mu \mathrm{m}$ as schematically illustrated in panel a. As particle concentration increases (higher $R_{0.65}$ ), the steepening impact of bluing is counterbalanced by the flattening impact of larger particle size near clouds, and so $R_{0.47}$ values close to and far from clouds are similar. Overall, while Fig. 2 cannot reveal the exact magnitude of bluing, it certainly suggests that it could be significant.

\section{Near-cloud enhancements in lidar backscatter and solar reflectance}

In Sects. 2 and 3, we reinforced earlier findings that both particle changes and 3-D radiative processes are significant near clouds using CALIOP and MODIS observations independently. Now we turn to a combined analysis of CALIOP and MODIS data for more details on these effects. This combined analysis uses CALIOP attenuated lidar backscatter profiles at both $532 \mathrm{~nm}$ and $1064 \mathrm{~nm}$ wavelengths, degraded from $333 \mathrm{~m}$ to $1 \mathrm{~km}$ horizontal resolution. It also uses MODIS data for $201 \mathrm{~km}$ wide swaths from NASA's A-train data depot at http://disc.sci.gsfc.nasa.gov/atdd/data-holdings. Specifically, the analysis uses the MODIS cloud mask (Ackerman et al., 1998; Frey et al., 2008) and $0.55 \mu \mathrm{m}$ solar reflectances provided at $1 \mathrm{~km}$ resolution, and also cloud top pressures provided at $5 \mathrm{~km}$ resolution (Menzel et al., 2008). We note that although CALIOP also provides cloud detection and cloud altitude, we use the MODIS products because they give information even for clouds lying next to the single along-track line sampled by CALIOP.

We co-locate MODIS and CALIOP data for the entire study period (November 2006-October 2007) by identifying the MODIS pixel with the closest geographical coordinates to each daytime CALIOP profile. While this co-location is not perfect (the main uncertainties are caused by parallax effects arising from differences in CALIOP and MODIS view directions, and by clouds drifting with the wind during the $1-$ 2 min between CALIPSO and Aqua overpasses), the results in Várnai and Marshak (2012) indicate that the uncertainties have little impact on median values for areas that lie farther than $1 \mathrm{~km}$ away from clouds.

Using the co-located CALIOP-MODIS dataset, we first examine near-cloud changes in the oceanic portions of the four areas highlighted in Fig. 3a. These areas were selected because they are characterized by widely different aerosol populations. Displaying the abundance of various aerosol types in coupled GOCART (Goddard Chemistry Aerosol Radiation and Transport) - GEOS-5 (Goddard Earth Observing System Data Assimilation System V5) (Chin et al., 2002; Rienecker et al., 2011) global reanalysis through the NASA Giovanni data system (Acker and Leptoukh, 2007) confirms this: Giovanni maps (not shown) indicate that areas (1)-(4) are dominated by (1) desert dust, (2) sulfates, (3) combination of desert dust and sulfates, and (4) black/organic carbon.

Figure $3 \mathrm{~b}$ shows the near-cloud relative enhancement in median particle scattering for each of the areas. These enhancements are calculated in two steps. In Step one, the contribution of (aerosol + undetected cloud) particle scattering is estimated for both CALIOP $532 \mathrm{~nm}$ backscatter vertically integrated below $3 \mathrm{~km}$ altitude $\left(\beta^{p}\right)$ and for MODIS $0.55 \mu \mathrm{m}$ reflectance $\left(R^{p}\right)$. For CALIOP, $\beta^{p}$ is obtained by removing from lidar attenuated backscatter values $\beta_{532}$ the effects of Rayleigh scattering and ozone absorption using the air and ozone molecular density profiles provided in the Level 1 
CALIOP product files. (These profiles are based on global reanalysis by the GEOS-5 model.) For MODIS, $R^{p}$ is obtained by removing from observed reflectance values $R_{0.55}$ the contributions of surface reflection and Rayleigh scattering. The combined surface and Rayleigh contributions are estimated as the reflectances expected for completely aerosoland cloud-free columns. These expected reflectances are obtained from the upcoming Collection 6 version of the operational MODIS aerosol retrieval algorithm, which considers wind speed values from the GEOS-5 reanalysis (Levy et al., 2013). In Step two, the relative enhancements of $\beta^{p}$ and $R^{p}$ are calculated by contrasting the medians for areas closer and farther than $5 \mathrm{~km}$ from clouds.

Figure $3 \mathrm{~b}$ shows not only that near-cloud enhancements are significant in all areas, but it also shows substantial regional differences. One reason for the differences is that the effect of clouds on desert dust is relatively small, partly because most of the dust transported from deserts over the ocean is in the free troposphere and above low boundary layer clouds; the only contribution comes from low dust particles mixed with marine aerosols (Koffi et al., 2012; Yang et al., 2012). In addition, regional variations in aerosol hygroscopicity or in the abundance of small, hard-to-detect clouds may also play a role.

The figure shows that in all cases near-cloud enhancements are larger for MODIS reflectances than for CALIOP backscatters. Because changes in particle populations (including both aerosols and undetected cloud droplets) should cause similar relative enhancements in particle scattering for CALIOP and MODIS (both the CALIOP and MODIS curves are obtained using the MODIS cloud mask), most of the extra enhancement likely arises from 3-D radiative processes and instrument blurring. In fact - as it will be discussed in Sect. 5 - particle changes should cause slightly higher relative enhancements for CALIOP than for MODIS data, which implies that 3-D radiative processes and instrument blurring are likely larger than suggested by this figure. While the extra enhancement is large in all areas, the regional variations indicate that other factors such as solar elevation, cloud albedo, and aerosol optical thickness also play a role in the relative importance of 3-D effects and blurring.

Figure 4 shows CALIOP and MODIS relative enhancements in particle scattering for all oceans between $60^{\circ} \mathrm{N}$ and $60^{\circ} \mathrm{S}$. The good agreement between CALIOP and MODIS curves far from clouds suggests that 3-D radiative processes and instrument blurring are insignificant farther than about $10 \mathrm{~km}$ from clouds. Within $5 \mathrm{~km}$ from clouds, however, MODIS enhancements significantly exceed CALIOP enhancements: the relative difference between the two enhancements near clouds is about $30 \%$ of MODIS enhancements. This implies that changes in aerosols and undetected cloud particles explain roughly two thirds $(70 \%)$ of MODIS reflectance enhancements near clouds, with the remaining third likely coming from 3-D and instrumental effects. The

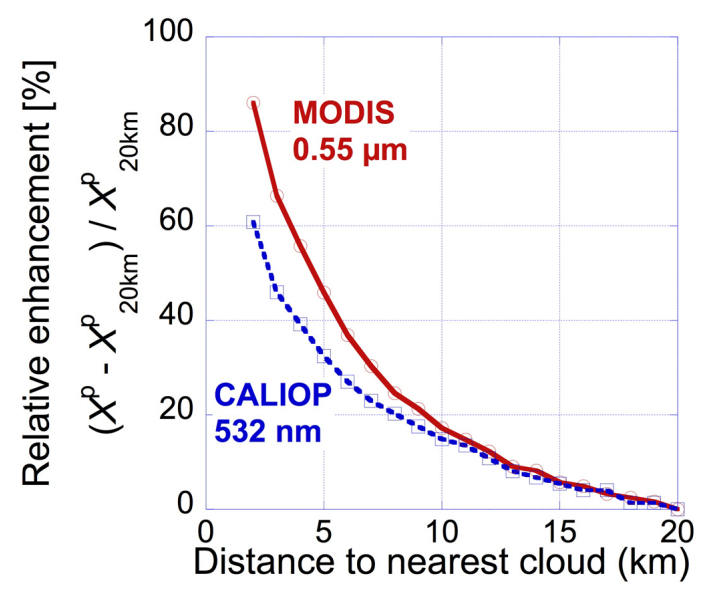

Fig. 4. Median near-cloud relative enhancements in particle scattering observed by MODIS and CALIOP over all oceans between $60^{\circ} \mathrm{N}$ and $60^{\circ} \mathrm{S}$. Relative enhancements (RE) are calculated using the equation $\mathrm{RE}=100\left(X-X_{20 \mathrm{~km}}\right) / X_{20 \mathrm{~km}}$, with $X$ being $R^{p}$ or $\beta^{p}$ for the two curves.

roles of these factors are further examined in the next section, which combines data analysis with theoretical modeling.

\section{Reasons for near-cloud enhancements of solar reflectance}

Many authors reported a positive correlation between aerosol optical thickness and cloud fraction retrieved using various platforms and algorithms (e.g., Ignatov et al., 2005; Kaufman et al., 2005; Loeb and Manalo-Smith, 2005; Loeb and Schuster, 2008). Most recently, a study by Chand et al. (2012) analyzing $11 \mathrm{yr}$ of MODIS observations found that $25 \%$ enhancement in cloud fraction leads to a 0.05 increase in clear sky optical depth. Several studies also documented systematic increases in MODIS clear-sky reflectances near clouds (Koren et al., 2007; Redemann et al., 2009; Várnai and Marshak, 2009). This section examines the relative importance of various factors contributing to the observed increases by combining CALIOP and MODIS data analysis with theoretical modeling.

Figure 5a compares the observed enhancements in MODIS $0.55 \mu \mathrm{m}$ reflectances to simulations of one portion of 3 -D enhancements: clouds in fully overcast $1 \mathrm{~km}^{2}$ size pixels scatter light into clear areas where molecular scattering redirects it toward the satellite. This contribution is estimated through 3-D radiative transfer simulations by a Monte Carlo model that was tested in the Intercomparison of 3-D Radiation Codes (I3RC) project (Cahalan et al., 2005). The simulations are performed for all clear pixels used for the MODIS and CALIOP data analysis in Fig. 4. The simulations rely on the operational MODIS cloud product to specify the spatial distribution of cloud properties (especially cloud optical thickness and cloud top pressure) around each clear pixel. 

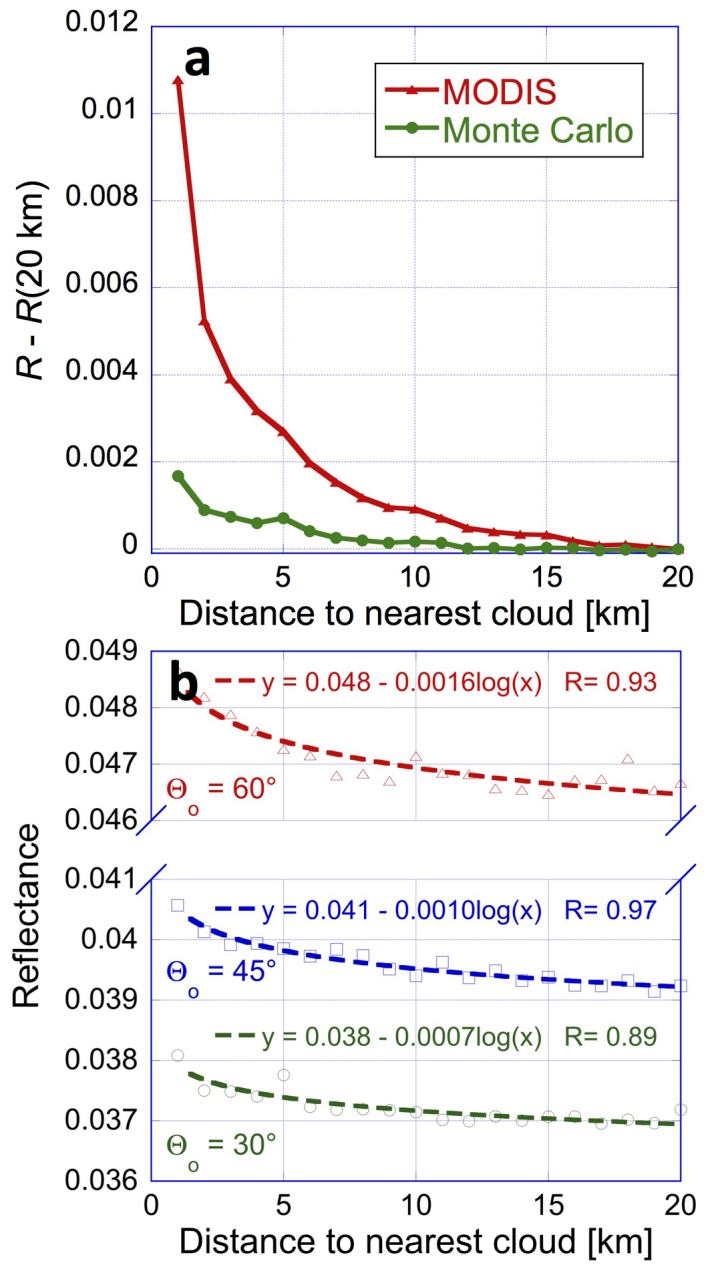

Fig. 5. (a) Comparison of $0.55 \mu \mathrm{m}$ mean reflectance enhancements observed by MODIS and simulated by a Monte Carlo model that considers the Rayleigh scattering component of 3-D radiative processes. Enhancements are defined as the difference from the mean value observed $20 \mathrm{~km}$ away from clouds. The plot is based on all oceanic areas between $60^{\circ} \mathrm{N}$ and $60^{\circ} \mathrm{S}$ that MODIS observed along the CALIOP track between November 2006 and October 2007. (b) Subsets of the Monte Carlo simulation results in Panel a for three solar zenith angle $\left(\Theta_{0}\right)$ values. Dashed lines show logarithmic fits to the data.

At present, the simulations include only cloud and Rayleigh scattering, but not aerosol and surface scattering. Moreover - in the absence of MODIS cloud products for partly cloudy and cloud edge pixels - the simulations do not include broken cumulus fields where the cloudy portion of these pixels contribute significantly to the 3-D enhancements. Nevertheless, the results in Fig. 5a show that the simulated component of 3-D enhancement explains $15-20 \%$ of the observed nearcloud enhancements, as the simulated values (green curve) are about $15-20 \%$ of the observed values (red curve). We plan to expand the Monte Carlo model and include the currently missing components of 3-D processes into future simulations.
Figure $5 \mathrm{~b}$ shows that the simulated near-cloud enhancements increase with solar zenith angle, for example they double between $30^{\circ}$ and $60^{\circ}$ solar zenith angles. This occurs mostly because MODIS provides systematically higher optical thickness values at higher latitudes where the sun is more oblique, and thicker clouds scatter more sunlight toward nearby clear areas. Only about a fifth $(20 \%)$ of the increase with solar zenith angle occurs due to increase in cloud reflectivity and oblique cloud reflection that allows more cloud-reflected light to travel to nearby clear areas for lower sun (Wen et al., 2008).

Figure 6 provides an initial overview of various factors contributing to the observed near-cloud enhancements in MODIS reflectances. The figure combines data analysis and Monte Carlo simulations with instrument blurring effects for the yearlong global oceanic dataset used in Figs. 4 and 5.

The black line in Fig. 6 indicates the observed increase in median MODIS $0.55 \mu \mathrm{m}$ nadir reflectance - that is, the difference from the median reflectance observed $20 \mathrm{~km}$ away from clouds $\left(R_{20 \mathrm{~km}}=0.061\right)$.

The blue area represents the reflectance increase attributed to particle changes, including both aerosol changes such as swelling and changes in undetected cloud droplet populations. The blue area is estimated in two steps. In Step one, the contribution of (aerosol + undetected cloud) particle scattering is estimated for both CALIOP vertically integrated $532 \mathrm{~nm}$ backscatter $\left(\beta^{p}\right)$ and for MODIS $0.55 \mu \mathrm{m}$ reflectance $\left(R^{p}\right)$ as described in the discussion of Fig. 3b in Sect. 4. In Step $t w o$, the particle contribution to MODIS reflectance enhancements (that is, the blue area in Fig. 6) is estimated by assuming that the near-cloud relative increase in particle scattering is the same for MODIS and CALIOP, and so for any distance to cloud $(d)$ value,

$R^{p}(d)=R^{p}(20 \mathrm{~km})+\frac{\beta^{p}(d)-\beta^{p}(20 \mathrm{~km})}{\beta^{p}(20 \mathrm{~km})} R^{p}(20 \mathrm{~km})$.

We note that using Eq. (1) likely overestimates the blue area for two reasons. First, the equation does not consider that near-cloud changes in particle size can change the scattering phase functions differently for lidar backscatter and for MODIS solar reflectance. The comparison of Mie calculations for the nine MODIS aerosol models (Remer et al., 2005) and for modified versions of these models where particle size is increased according to hydration calculations (e.g., Gassó et al., 2000) suggests that ignoring phase function changes has especially strong effects for coarse mode aerosols and might overestimate the blue area by 10 $20 \%$ - though this issue will require further detailed analysis. The second reason why we may overestimate the blue area is that since we use the same MODIS cloud mask for both MODIS and CALIOP data, cloud contamination may give a larger boost to CALIOP near-cloud enhancements: differences in CALIOP and MODIS field-of-views and clouds drifting or developing during the 1-2 min between MODIS and CALIOP observations may result in cloud 


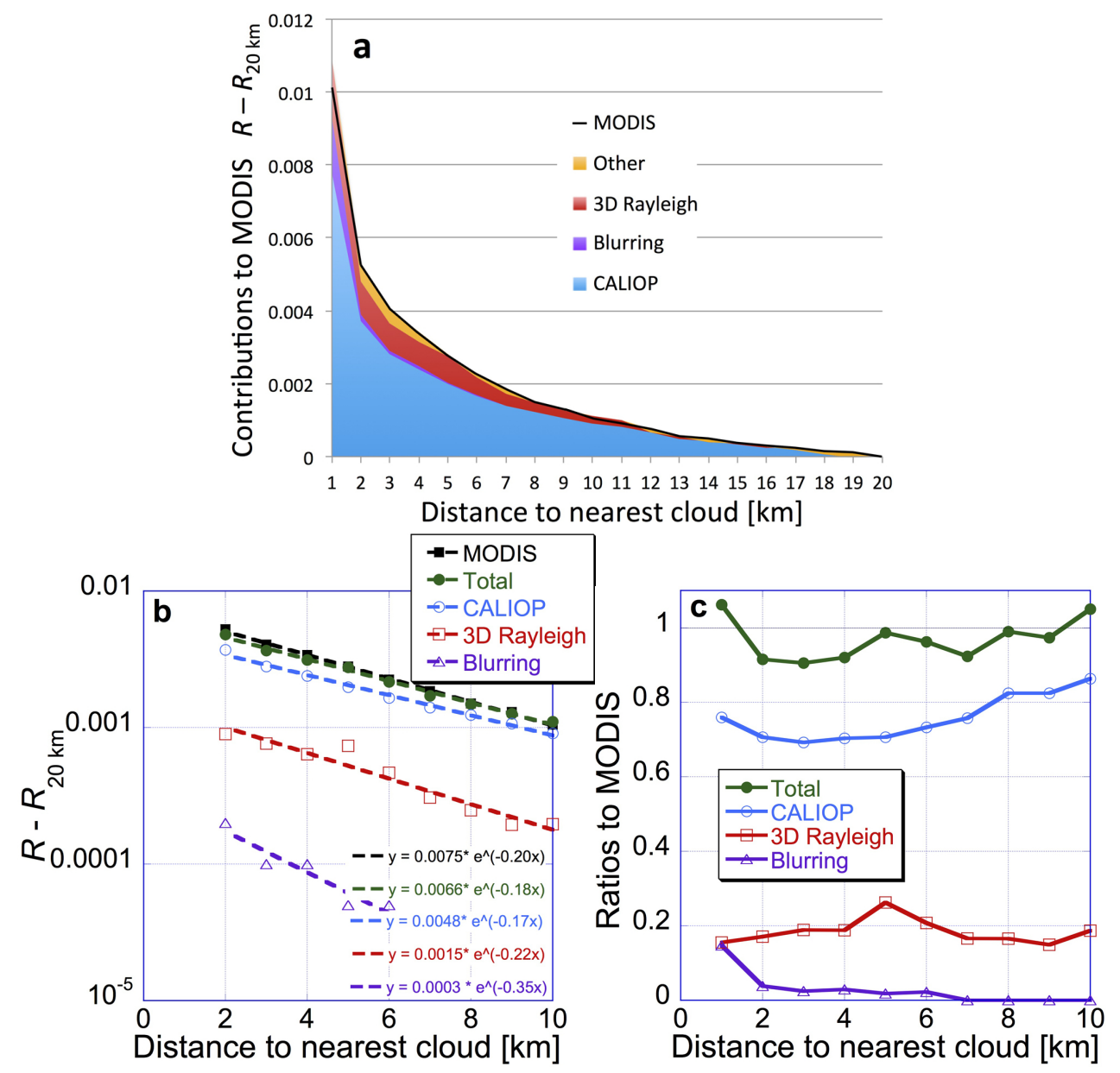

Fig. 6. Estimated contribution of various factors to the observed near-cloud increase in median MODIS 0.55 $\mu \mathrm{m}$ reflectances (black line). The increase is defined as the difference from the median value observed $20 \mathrm{~km}$ away from clouds. (a) Blue (CALIOP): changes in particle populations, including both aerosol changes such as swelling and changes in undetected cloud particles. Purple (Blurring): instrument blurring. Red (3-D Rayleigh): the part of 3-D bluing enhancement that involves cloud scattering in overcast cloud interior pixels and subsequent Rayleigh scattering in clear air. Orange (Other): contributions not yet attributed to a specific process, including 3-D enhancements involving cloud scattering near cloud edges, aerosol scattering, and surface reflection. (b) Contributions of various factors on a logarithmic scale. The data labeled "Total" shows the sum of CALIOP, 3-D Rayleigh, and PSF contributions. The dashed lines and equations indicate logarithmic fits; the correlation coefficients $(R)$ exceed 0.95 . (c) Ratio of enhancements attributed to various factors and the enhancements observed by MODIS.

droplets affecting CALIOP data even if the corresponding MODIS observation is cloud free. As a result, the blue area is considered a likely overestimate or upper bound of enhancements due to particle changes.

The purple area in Fig. 6a represents the impact of MODIS instrument blurring. This is estimated by applying the instrument point spread function (PSF) (Meister and McClain, 2010) to the observed MODIS reflectance fields. One complication we should mention here is that accurate PSFs are available only for MODIS ocean bands, and not for the $0.55 \mu \mathrm{m}$ atmospheric band used in operational aerosol retrievals. Fortunately, we can apply the $0.53 \mu \mathrm{m}$ ocean band PSF to $0.55 \mu \mathrm{m}$ data with confidence, as the two bands display practically identical near-cloud enhancements (not shown).

The red area represents the 3-D radiative enhancements estimated by the Monte Carlo simulations of Fig. 5a. As mentioned above, these enhancements occur when clouds scatter light into nearby clear-sky columns, where air molecules redirect it toward the satellite.

Finally, the orange area represents the enhancements not yet attributed to a specific process. This includes 3-D effects not yet considered in our simulations - for example 3-D effects caused by partly cloudy pixels, by aerosol, and by surface. We expect that future refinements (especially the addition of surface, aerosols, and partly cloudy pixels to the Monte Carlo simulations) will greatly reduce the orange area. 
We note that at a few spots the combined estimate (CALIOP+PSF+3-D Rayleigh) slightly exceeds the observed enhancement in MODIS reflectances. This occurs probably because, as mentioned above, the CALIOP portion, which corresponds to particle changes near clouds, is likely overestimated. Uncertainties in the Monte Carlo results may also play a role in the overestimations, especially $10-11 \mathrm{~km}$ away from clouds.

Still, even the current results allow us to conclude that changes in particle populations (blue area) are responsible for roughly two thirds of MODIS $0.55 \mu \mathrm{m}$ reflectance enhancements near clouds, and that 3-D radiative effects (red and orange areas) also play an important role, while instrument blurring (purple area) plays a fairly modest role farther than $1 \mathrm{~km}$ away from clouds.

Figure $6 \mathrm{~b}$ shows the enhancements attributed to various processes on a logarithmic scale. The enhancements are fit with an exponential function: $y=a \exp (-b x)$ where $x$ is the distance to the nearest cloud, and coefficient $b$ indicates the rate of enhancement decay with distance from clouds. We mention that exponential behavior near clouds was noted in earlier studies (e.g., Tackett and Di Girolamo, 2009). This panel reveals that instrument effects drop fastest with distance to clouds, 3-D effects drop much slower, and particle changes (seen in CALIPSO observations) even a bit slower. While the rate of drop for the total estimate is similar to that for particle changes, the rate for MODIS observations is slightly steeper. This suggests that the yet unexplained part of enhancements have a steeper slope than the current total estimate, and hence is more likely to come from notyet-considered 3-D effects (involving surface reflection, etc.) than from underestimations of particle contributions.

Finally, Fig. 6c shows what ratio of observed enhancements is attributed to various factors in our current initial estimates. The results show that particle changes (including changes in aerosols and undetected cloud particles) account for $2 / 3$ to $85 \%$ of observed enhancements, and that the relative importance of this contribution increases at larger distances from clouds. (In fact it dominates at distances larger than $10 \mathrm{~km}$.) As discussed above, however, these results are likely to overestimate the real particle effects and will need to be refined in future studies. On average, 3-D Rayleigh effects account for roughly $20 \%$ of observed enhancements. Right next to clouds instrument effects account for roughly $15 \%$ of enhancements, but this contribution quickly becomes negligible at larger distances.

While it is difficult to estimate uncertainties in our current initial estimates in a consistent manner for all factors, the total estimate (green curve) being within 5-10\% of the observations (value of 1 in Fig. 6c) suggests modest uncertainties. However, this will need to be re-confirmed once our simulations include the not-yet-considered 3-D enhancements caused by surface and aerosol scattering and partly cloudy pixels.

\section{Summary}

The purpose of this study is to better understand and measure aerosol properties near low-level maritime clouds. Improving the interpretation of near-cloud aerosol measurements is important for assessing two critical aspects of climate and human impacts on climate: aerosol-cloud interactions and the direct radiative effect of aerosols. To better understand systematic near-cloud changes in particle properties and satellite-observed solar reflectances, the study combines the analysis of co-located A-train data from the CALIOP lidar and MODIS imager with theoretical simulations of 3-D radiative processes and instrument blurring. The analysis is performed for a yearlong dataset covering all oceans between $60^{\circ} \mathrm{N}$ and $60^{\circ} \mathrm{S}$.

Near-cloud changes in histograms of CALIOP attenuated backscatter and color ratio observations confirm earlier findings of increased optical thickness and particle size near clouds. The observed behavior is consistent with near-cloud processes, such as aerosol swelling in humid air and the presence of undetected cloud particles.

However, the spectral dependence of MODIS reflectances is consistent not only with increasing particle size near clouds, but also with a strong 3-D radiative process called "bluing". Since MODIS spectral dependence alone cannot reveal the exact magnitude of 3-D radiative processes, the paper combines the analysis of co-located MODIS and CALIOP data with theoretical simulations of 3-D radiative transfer and MODIS instrument blurring. It estimates the role of particle changes in creating the observed MODIS reflectance enhancements by comparing the relative enhancements in particle scattering observed by CALIOP and MODIS data. This helps because CALIOP data is affected only by particle changes, and not by the 3-D radiative processes and instrument blurring that influence MODIS observations. The results indicate that overall, near-cloud changes in particle populations - including both aerosols and undetected cloud particles - are responsible for roughly two thirds of the observed increase in $0.55 \mu \mathrm{m}$ MODIS reflectance. However, near-cloud relative enhancements show large regional variations, and are smallest in regions where the aerosol population includes large amounts of high-altitude desert dust not affected by low-level clouds.

Finally, theoretical simulations for the analyzed yearlong dataset indicate that neither instrument effects nor 3-D radiative processes contribute significantly to the enhancements observed farther than $10 \mathrm{~km}$ from clouds. Within $10 \mathrm{~km}$ from clouds - where the majority of clear-sky areas occur - the simulations indicate that while instrument effects are fairly modest, 3-D radiative processes contribute significantly to the observed enhancements. This occurs even though current simulations represent only one portion of 3-D enhancements: clouds in fully overcast $1 \mathrm{~km}^{2}$ size pixels scattering light into clear areas where Rayleigh scattering redirects the light toward the satellite sensor. We expect that future refinements - 
especially the addition of surface, aerosols, and partly cloudy pixels to the Monte Carlo simulations - will further increase the identified contribution of 3-D radiation and will reduce the portion of reflectance enhancements not yet attributed to a specific process.

Overall, the study provided further indications that cloudrelated particle changes and 3-D radiative effects are important in the at least half of all clear areas that lie in the vicinity of low clouds. This implies that aerosol retrievals are biased near clouds if all reflectance changes are attributed to changes in particle populations. However, excluding the problematic near-cloud areas affected by 3-D enhancements would cause sampling biases by ignoring particle changes occurring around clouds. Thus it is important to develop new methods that can provide accurate aerosol retrievals even in the near-cloud regions affected by 3-D radiative enhancements. Some recently proposed approaches offer new opportunities in this regard (e.g., Kassianov and Ovtchinnikov, 2008; Marshak et al., 2008). Finally, we expect that more detailed characterizations of near-cloud changes will provide new insights based on new high-resolution aerosol products, for example $3 \mathrm{~km}$-resolution data in the upcoming Collection 6 of the MODIS aerosol product, or $1 \mathrm{~km}$-resolution MODIS aerosol retrievals over land (Lyapustin et al., 2011) or ocean (Ahmad et al., 2010).

Acknowledgements. We gratefully acknowledge support for this research by the NASA Radiation Sciences Program managed by Hal Maring and by the NASA CALIPSO project supervised by Charles Trepte as the technical officer. We are grateful to Robert Levy for giving us the Collection 6 version of the operational MODIS aerosol retrieval code.

Edited by: O. Dubovik

\section{References}

Acker, J. G. and Leptoukh, G.: Online analysis enhances use of NASA earth science data, Eos Trans. AGU, 88, p. 14 and 17, 2007.

Ackerman, S. A., Strabala, K. I., Menzel, W. P., Frey, R. A., Moeller, C. C., and Gumley, L. E.: Discriminating clear sky from clouds with MODIS, J. Geophys. Res., 103, 32141-32157, doi:10.1029/1998JD200032, 1998.

Ahmad, Z., Franz, B. A., McClain, C. R., Kwiatkowska, E. J., Werdell, J., Shettle, E. P., and Holben, B. N.: New aerosol models for the retrieval of aerosol optical thickness and normalized water-leaving radiances from the SeaWiFS and MODIS sensors over coastal regions and open oceans, Appl. Optics, 49, 55455560, 2010.

Bar-Or, R. Z., Koren, I., and Altaratz, O.: Estimating cloud field coverage using morphological analysis, Environ. Res. Lett., 5, 014022, doi:10.1088/1748-9326/5/1/014022, 2010.

Bar-Or, R. Z., Altaratz, O., and Koren, I.: Global analysis of cloud field coverage and radiative properties, using morphologi- cal methods and MODIS observations, Atmos. Chem. Phys., 11, 191-200, doi:10.5194/acp-11-191-2011, 2011.

Bar-Or, R. Z., Koren, I., Altaratz, O., and Fredj, E.: Radiative properties of humidified aerosols in cloudy environment, Atmos. Res., 118, 280-294, 2012.

Cahalan, R. F., Oreopoulos, L., Marshak, A., Evans, K. F., Davis, A. B., Pincus, R., Yetzer, K., Mayer, B., Davies, R., Ackerman, T., Barker, H., Clothiaux, E., Ellingson, R., Garay, M., Kassianov, E., Kinne, S., Macke, A., O'Hirok, W., Partain, P., Prigarin, S., Rublev, A., Stephens, G., Szczap, F., Takara, E., Várnai, T., Wen, G., and Zhuravleva, T.: The International Intercomparison of 3D Radiation Codes (I3RC): Bringing together the most advanced radiative transfer tools for cloudy atmospheres, B. Am. Meteorol. Soc., 86, 1275-1293, 2005.

Chand, D., Wood, R., Ghan, S. J., Wang, M., Ovchinnikov, M., Rasch, P. J., Miller, S., Schichtel, B., and Moore, T.: Aerosol optical depth increase in partly cloudy conditions, J. Geophys. Res., 117, D17207, doi:10.1029/2012JD017894, 2012.

Charlson, R., Ackerman, A., Bender, F., Anderson, T., and Liu, Z.: On the climate forcing consequences of the albedo continuum between cloudy and clear air, Tellus, 59, 715-727, 2007.

Chin, M., Ginoux, P., Kinne, S., Torres, O., Holben, B. N., Duncan, B. N., Marin, R. V., Logan, J. A., Higurashi, A., and Nakajima, T.: Tropospheric aerosol optical thickness from the GOCART model and comparisons with satellite and sun photometer measurements, J. Atmos. Sci., 59, 461-483, 2002.

Dubovik, O. V., Lapyonok, T. V., and Oshchepkov, S. L.: Improved technique for data inversion: optical sizing of multicomponent aerosols, Appl. Optics, 34, 8422-8436, 1995.

Frey, R. A., Ackerman, S. A., Liu, Y., Strabala, K. I., Zhang, H., Key, J. R., and Wang, X.: Cloud Detection with MODIS. Part I: Improvements in the MODIS Cloud Mask for Collection 5, J. Atmos. Ocean. Tech., 25, 1057-1072, 2008.

Gassó, S., Hegg, D. A., Covert, D. S., Collins, D., Noone, K. J., Öström, E., Schmid, B., Russell, P. B., Livingston, J. M., Durkee, P. A., and Jonsson, H.: Influence of humidity on the aerosol scattering coefficient and its effect on the upwelling radiance during ACE-2, Tellus B, 52, 546-567, doi:10.1034/j.16000889.2000.00055.x, 2000.

Ignatov, A., Minnis, P., Loeb, N., Wielicki, B., Miller, W., SunMack, S., Tanre, D., Remer, L., Laszlo, I., and Geier, E.: Two MODIS aerosol products over ocean on the Terra and Aqua CERES SSF, J. Atmos. Sci., 62, 1008-1031, 2005.

Kassianov, E. I. and Ovtchinnikov, M.: On reflectance ratios and aerosol optical depth retrieval in the presence of cumulus clouds, Geophys. Res. Lett., 35, L06807, doi:10.1029/2008GL033231, 2008.

Kaufman, Y. J., Koren, I., Remer, L. A., Tanré, D., Ginoux, P., and Fan, S.: Dust transport and deposition observed from the Terra- Moderate Resolution Imaging Spectroradiometer (MODIS) spacecraft over the Atlantic Ocean, J. Geophys. Res. 110, D10S12, doi:10.1029/2003JD004436, 2005.

Koffi, B., Schulz, M., Bréon, F.-M., Griesfeller, J., Winker, D., Balkanski, Y., Bauer, S., Berntsen, T., Chin, M., Collins, W. D., Dentener, F., Diehl, T., Easter, R., Ghan, S., Ginoux, P., Gong, S., Horowitz, L. W., Iversen, T., Kirkevåg, A., Koch, D., Krol, M., Myhre, G., Stier, P., and Takemura, T.: Application of the CALIOP layer product to evaluate the vertical distribution of aerosols estimated by global models: AeroCom phase I results, 
J. Geophys. Res., 117, D10201, doi:10.1029/2011JD016858, 2012.

Koren, I., Remer, L. A., Kaufman, Y. J., Rudich, Y., and Martins, J. V.: On the twilight zone between clouds and aerosols, Geophys. Res. Lett., 34, L08805, doi:10.1029/2007GL029253, 2007.

Koren, I., Feingold, G., Jiang, H., and Altaratz, O.: Aerosol effects on the inter-cloud region of a small cumulus cloud field, Geophys. Res. Lett., 36, L14805, doi:10.1029/2009GL037424, 2009.

Levy, R. C., Mattoo, S., Munchak, L. A., Remer, L. A., Sayer, A. M., and Hsu, N. C.: The Collection 6 MODIS aerosol products over land and ocean, Atmos. Meas. Tech. Discuss., 6, 159-259, doi:10.5194/amtd-6-159-2013, 2013.

Loeb, N. G. and Manalo-Smith, N.: Top-of-atmosphere direct radiative effect of aerosols over global oceans from merged CERES and MODIS observations, J. Climate, 18, 3506-3526, 2005.

Loeb, N. G. and Schuster, G. L.: An observational study of the relationship between cloud, aerosol and meteorology in broken low-level cloud conditions, J. Geophys. Res., 113, D14214, doi:10.1029/2007JD009763, 2008.

Lyapustin, A., Wang, Y., Lászlo, I., Kahn, R., Korkin, S., Remer, L., Levy, R., and Reid, J.: Multi-Angle implementation of atmospheric correction (MAIAC): Part 2. Aerosol algorithm, J. Geophys. Res., 116, D03211, doi:10.1029/2010JD014986, 2011.

Marshak, A., Wen, G., Coakley, J., Remer, L., Loeb, N. G., and Cahalan, R. F.: A simple model for the cloud adjacency effect and the apparent bluing of aerosols near clouds, J. Geophys. Res., 113, D14S17, doi:10.1029/2007JD009196, 2008.

Meister, G. and McClain, C. R.: Point-spread function of the ocean color bands of the Moderate Resolution Imaging Spectroradiometer on Aqua, Appl. Optics, 49, 6276-6285, 2010.

Menzel, W. P., Frey, R. A., Zhang, H., Wylie, D. P., Moeller, C. C., Holz, R. E., Maddux, B., Baum, B. A., Strabala, K. I., and Gumley, L. E.: MODIS Global Cloud-Top Pressure and Amount Estimation: Algorithm Description and Results, J. Appl. Meteorol. Clim., 47, 1175-1198, doi:10.1175/2007JAMC1705.1, 2008.

Redemann, J., Zhang, Q., Russell, P. B., Livingston, J. M., and Remer, L. A.: Case studies of aerosol remote sensing in the vicinity of clouds, J. Geophys. Res., 114, D06209, doi:10.1029/2008JD010774, 2009.

Remer, L. A., Kaufman, Y. J., Tanre, D., Mattoo, S., Chu, D. A., Martins, J. V., Li, R. R., Ichoku, C., Levy, R. C., Kleidman, R. G., Eck, T. F., Vermote, E., and Holben, B. N.: The MODIS aerosol algorithm, products and validation, J. Atmos. Sci., 62, 947-973, 2005.

Rienecker, M. M., Suarez, M. J., Gelaro, R., Todling, R., Bacmeister, J., Liu, E., Bosilovich, M. G., Schubert, S. D., Takacs, L., Kim, G.-K., Bloom, S., Chen, J., Collins, D., Conaty, A., Da Silva, A., Gu, W., Joiner, J., Koster, R. D., Lucchesi, R., Molod, A., Owens, T., Pawson, S., Pegion, P., Redder, C. R., Reichle, R., Robertson, F. R., Ruddick, A. G., Sienkiewicz, M., and Woollen, J.: MERRA: NASAs modern-era retrospective analysis for research and applications, J. Climate, 24, 3624-3648, 2011.
Solomon, S., Qin, D., Manning, M., Chen, Z., Marquis, M., Averyt, K. B., Tignor, M., and Miller, H. L.: Climate Change 2007: The Physical Science Basis. Contribution of Working Group I to the Fourth Assessment. Report of the Intergovernmental Panel on Climate Change, Cambridge University Press, Cambridge, United Kingdom and New York, NY, USA, 996 pp., 2007.

Su, W., Schuster, G. L., Loeb, N. G., Rogers, R. R., Ferrare, R. A., Hostetler, C. A., Hair, J. W., and Obland, M. D.: Aerosol and cloud interaction observed from high spectral resolution lidar data, J. Geophys. Res., 113, D24202, doi:10.1029/2008JD010588, 2008.

Tackett, J. L. and Di Girolamo, L.: Enhanced aerosol backscatter adjacent to tropical trade wind clouds revealed by satellite-based lidar, Geophys. Res. Lett., 36, L14804, doi:10.1029/2009GL039264, 2009.

Twohy, C. H., Coakley Jr., J. A., and Tahnk, W. R.: Effect of changes in relative humidity on aerosol scattering near clouds, J. Geophys. Res., 114, D05205, doi:10.1029/2008JD010991, 2009.

Várnai, T. and Marshak, A.: MODIS observations of enhanced clear sky reflectance near clouds, Geophys. Res. Lett., 36, L06807, doi:10.1029/2008GL037089, 2009.

Várnai, T. and Marshak, A.: Global CALIPSO observations of aerosol changes near clouds, Geosci. Remote Sens. Lett., 8, 1923, 2011.

Várnai, T. and Marshak, A.: Analysis of co-located MODIS and CALIPSO observations near clouds, Atmos. Meas. Tech., 5, 389-396, doi:10.5194/amt-5-389-2012, 2012.

Wen, G., Marshak, A., Cahalan, R. F., Remer, L. A., and Kleidman, R. G.: 3-D aerosol-cloud radiative interaction observed in collocated MODIS and ASTER images of cumulus cloud fields, J. Geophys. Res., 112, D13204, doi:10.1029/2006JD008267, 2007.

Wen, G., Marshak, A., and Cahalan, R. F.: Importance of molecular Rayleigh scattering in the enhancement of clear sky radiance in the vicinity of boundary layer cumulus clouds, J. Geophys. Res., 113, D24207, doi:10.1029/2008JD010592, 2008.

Yang, W., Marshak, A., Várnai, T., and Liu, Z.: Effect of CALIPSO cloud aerosol discrimination (CAD) confidence levels on observations of aerosol properties near clouds, Atmos. Res., 116, 134 141, 2012. 